\title{
LA "REFORMA AGRARIA": UNA REPETIDA NECESIDAD DE LA AGRICULTURA EN EL CAPITALISMO
}

\author{
J.F. OJEDA RIVERA, \\ J.L. DIAZ QUIDIELLO, \\ C. MARQUEZ GUERRERO y \\ J.M. LOPEZ GARCIA *
}

\section{INTRODUCCION}

EI presente artículo pretende situar el momento actual de la agricultura andaluza dentro de un contexto histórico y unas coordenadas espaciales más ámplias que ayuden a esclarecer el significado real de la crisis que atraviesa y de la panacea que se presenta como solución: la "reforma agraria". Esto nos ha llevado a poner en cuestión algunos de los aspectos sobre los que ha venido girando el debate en torno a dicha "reforma agraria" durante los últimos meses, tratando de subrayar la necesidad de otras alternativas a las oficialmente aceptadas.

Ante un panorama tan aplastantemente dominado por un posibilismo claudicante y pesimista como es el español, cualquier búsqueda de nuevos caminos puede ser considerada utópica, pero no por ello tiene que ser negativa. Es más, quizás deba de ser esa una de las tareas prioritarias de la Universidad dentro de la sociedad: reivindicar de nuevo la utopía y denunciar la radical separación que se está dando entre los planteamientos teóricos y la acción práctica, entre lo que ha venido defendiendo la intelectualidad progresista española y sus realizaciones al llegar al poder. $\mathrm{Y}$ todo ello porque, tal vez detrás de tantas alabanzas al pragmatismo y tantas conversiones al neoliberalismo no se esconda más que la falta de la imaginación necesaria para afrontar, con nuevas ideas, la crisis irreversible del modelo de crecimiento desarrollista de las últimas décadas.

* En este artículo se recogen parte de las discusiones de un seminario que sobre el mismo tema han llevado a cabo los alumnos de práctica de Geografia $R$ ural de $40^{\circ}$ curso, en Sevilla, durante el segundo cuatrimestre del curso 1983-1984, coordinados por el profesor J.F. Ojeda Rivera. 
Parece inevitable que en los momentos más críticos de la agricultura, muchos investigadores hayan acudido a la historia para percibir de ella alguna luz que haga más visible el camino futuro. En nuestro seminario ha primado este recurso histórico que nos ha puesto de manifiesto dos realidades que pueden ser consideradas como las claves interpretativas de la situación agraria actual: una de ellas es la existencia de una crisis que muy bien podrá diagnosticarse como crónica, ya que habiendo presentado sus primeros síntomas a finales del siglo XVIII, aún está por solucionar de forma satisfactoria. La "cuestión agraria" unas veces con mayor virulencia que otras ha aparecido intermitentemente a lo largo de los dos últimos siglos. La inadaptación de la agricultura como sistema productivo al modo de producción capitalista parece ser el factor condicionante de tal situación.

A esta crisis más o menos permanente se ha intentado aplicar - y esta es la segunda realidad descubierta por el recorrido histórico efectuado- sucesivos programas reformistas en los momentos de mayor conflictividad social. $\mathrm{Y}$ dichas reformas se planteaban simultaneamente desde dos puntos de vista: uno, el oficial, que proponía "proyectos reformistas para que nada cambiase" (BERNAL, 1984. 1); otro, el que hoy denominaríamos "alternativo", y que en ningún caso llegaría a materializarse prácticamente salvo en los excepcionales momentos de la guerra civil.

Volvemos hoy, por tanto, a una situación que no es completamente nueva en la historia contemporánea de España y Andalucía, pués, en definitiva, la "reforma agraria" entendida como transformaciones en las estructuras agrarias encaminadas a una modernización y a su consecuente aumento de producciones y rendimientos, es una necesidad del mismo sistema capitalista a cuyos principios de ampliación continuada de capital, obtención progresiva de plusvalía y monopolio, no parecen adaptarse ni las estructuras ni las producciones agrarias.

\section{LA AGRICULTURA DEL ANTIGUO REGIMEN}

La acumulación de experiencias en la relación hombre-medio había llegado a un punto culminante a mediados del siglo XVIII, fecha cumbre del Antiguo Régimen. El Catastro del Marqués de la Ensenada (1.751-61) presenta una agricultura equilibrada y relativamente estable que pretende cubrir las necesidades de supervivencia de las poblaciones manteniendo, a su vez, cierto respeto por el factor tierra, que aseguraba una explotación de ésta ecológicamente óptima (LOPEZ ONTIVEROS, ANT., 1984).

El territorio agrario tradicional se caracterizaba por una organización del espacio en franjas concéntricas y especializadas que se sitúan en torno a los 
núcleos de población (ruedos), según el modelo elaborado por Von Thünen que correlaciona intensidad con proximidad al núcleo poblacional principal (mercado).

En la génesis y permanencia de estos paisajes agrarios tradicionales destaca el protagonismo del medio físico, consecuencia del bajo desarrollo tecnológico: Extensos espacios incultos - serranías, arenales, marismas y hasta suelos de bujeo conquistados para el laboreo sistemático ya en pleno siglo XIX (GONZALEZ BERNALDEZ, F., 1981)-, largos períodos de barbecho, escasa o nula fertilización... Todo ello hacía posible un equilibrio entre la realidad ecológica y la creación humana, pero al mismo tiempo, impedía la formación de un excedente que permitiese a los municipios obtener los alimentos necesarios de los intercambios con otras regiones. En tal situación se observa, analizando algunos datos del Catastro de Ensenada, cómo aquellas agriculturas municipales mantienen una verdadera obsesión por asegurar la autosuficiencia en las producciones básicas, es decir, los cereales y la ganadería. Dichas producciones, perfectamente integradas y complementarias exigian, a su vez, unos tipos de explotaciones extensivas ---cortijos con sus clásicos cultivos al tercio, dehesas, rozas, etc.- que se constituyen en componentes indispensables y verdaderamente articuladores de los diferentes terruños municipales.

En lo referido a las estructuras de la propiedad, el Antiguo Régimen se caracterizaba por el predominio de una apropiación estamental y vinculada de la tierra, en la que hay que destacar el papel jugado por las tierras de uso comunal. Eran una fuente directa de materias primas y energía, se utilizaban sus pastos para el ganado, en ellas se cazaba, pescaba, predaba... pero, además, desempeñaban una trascendental función dentro del agrosistema tradicional: El ser una válvula de escape de los conflictos sociales. En los momentos más delicados, en los que por catástrofes climatológicas o por crisis socioeconómicas los braceros y los pequeños campesinos se encontraban en situaciones límites, los espacios libres y no cultivados --baldíos de uso comunal-eran puestos en explotación solucionándose así las necesidades más urgentes.

Los regímenes de tenencia destacan por el absentismo de los propietarios y la cesión de la explotación a los colonos por medio de arrendamientos muy variables.

La continuidad en la ordenación del espacio agrario con sus bajos niveles de explotación y la estabilidad en las formas de propiedad y tenencia de la tierra no son ajenas al estancamiento de la población que define el ciclo demográfico antiguo. Las bajas tasas de crecimiento permitían dejar fuera de la producción grandes extensiones de tierra y al mismo tiempo hacían innecesaria las transformaciones tecnológicas que aumentasen la productividad de las explotaciones.

El agrosistema tradicional había creado una serie de mecanismos que ayudaban a salvar las contradicciones internas provocadas por el mismo. Así 
la conflictividad social generada por la profunda bipolarización que caracterizaba la estructura de cualquier sociedad del Antiguo Régimen aparecía atenuada por la disponibilidad de tierras que el escaso desarrollo de las fuerzas productivas mantenía fuera de explotación y que tradicionalmente eran consideradas como baldíos o tierras de aprovechamiento comunal.

El final de aquel orden de cosas establecido a lo largo de muchos siglos, resultará un capítulo bastante traumático para la agricultura y para todo el mundo rural en su conjunto. Aquel equilibrio secular se irá desmantelando a lo largo del s.XIX y caerá definitivamente pulverizado tras la "modernización" de los años 60 de nuestro siglo. El desprecio a la armonía alcanzada en el campo ecológico, energético y socioeconómico unido al derroche consecuente a una intensificación desenfrenada del proceso productivo, que ha esquilmado el factor tierra, son características fundamentales de las transformaciones que el modo de producción capitalista ha propiciado en el sector agrario, en aras de un concepto unilateral del desarrollo. (TARRAFETA PUYAL, L., 1975).

\section{AGRICULTURA Y REVOLUCION BURGUESA}

Cuando en el s.XVIII se inicia un lento, pero continuado crecimiento demográfico consecuencia de la disminución de la tasa de mortalidad y de la política reformista de los Borbones, el agrosistema tradicional perdió una de las bases de su estabilidad. Era necesaria una revolución agrícola para cubrir la demanda provocada tanto por el incremento de la población en términos absolutos, como por las exigencias de mayor calidad presentada por la burguesía. La vieja agricultura con sus tierras improductivas y sus prácticas comunitarias propias de unas relaciones de producción precapitalistas, se mostró pronto totalmente íneficaz (FONTANA, J., 1978).

La apropiación estamental de la tierra, otro de los rasgos definitorios del Antiguo Régimen, representaba una contradicción demasiado evidente con la nueva situación social y económica como para que pudiese mantenerse a largo plazo. Además de dificultar el aumento de la producción, suponía un obstáculo para la reproducción ampliada de capital y el libre mercado de tierras que constituían las leyes doradas del nuevo sistema económico que la naciente burguesía estaba queriendo implantar. La existencia de un volumen considerable de tierras vinculadas o amortizadas y, por lo tanto, fuera del circuito del libre mercado era inadmisible para los postulados liberales que comenzaban a imponerse.

Lo inevitable de una reforma agraria fué percibido por los diferentes grupos que ocupaban la cúspide de la pirámide social tradicional - nobles, eclesiásticos, comerciantes adinerados y grandes arrendatarios-- antes de que esta se llevase a cabo oficialmente. Esta percepción se traduce de hecho en la 
adopción de unas medidas "ilegales" que pueden ser consideradas como auténticas "prereformas agrarias" efectuadas por los elementos más capacitados del Antiguo Régimen, futuros burgueses*.

$\mathrm{Al}$ fin, desde instancias estatales se propicia la puesta en marcha de unos planes de reforma con objetivos muy concretos: liberalizar el mercado de la tierra y consagrar el principio de la necesaria modernización agrícola. Todo ello desarrollado en un contexto de acuciantes necesidades pecuniarias de la Hacienda Pública, convertidas desde Godoy en el objetivo fundamental, aunque implícito, de dichas reformas (TOMAS Y VALIENTE, F., 1977).

Algunos teóricos del momento, preocupados por las consecuencias sociales de tales proyectos, defendieron otros modelos alternativos de trasformación de las estructuras agrarias que son criticados por idealistas y carentes de viabilidad práctica (TOMAS Y VALIENTE, F., 1977). Los proyectos de la burguesía triunfante, que quedarán plasmados en los decretos desvinculadores y desamortizadores, eran pués plenamente conscientes de sus objetivos y resultarán satisfactoriamente benéficos para sus autores, por lo que no cabe - desde posiciones actuales preocupadas por el tema social- achacar sus resultados, no propicios al igualitarismo, a infortunios del devenir histórico.

La nueva clase de propietarios que va emergiendo actuará siempre con criterios de máximo beneficio y mínimos riesgos en la explotación de sus ampliadas fincas. Romperá los contratos enfitéuticos acortando la duración de los arrendamientos o implantará el sistema de aparcería cuando la coyuntura económica así lo aconseje. Las nuevas condiciones, verdaderamente revolucionarias desde el punto de vista jurídico (CLAVERO, B., 1979) no permitían ya vivir al propietario de sus derechos feudales y ello explica que este tenga la necesidad de obtener el máximo beneficio de la explotación de Ia tierra, aplicando criterios capitalistas a la gestión de sus propiedades.

Las diez millones de hectáreas (SIMON SEGURA, F. 1973) que se suponen fueron vendidas a causa de los decretos desamortizadores de 1836 y 1855, más aquellas grandes extensiones que pasaran a ser consideradas como propiedades privadas de los antiguos señores, sirvieron para poner fin a la apropiación estamental de la tierra, sustituyéndola por el dominio absoluto de la propiedad privada y la implantación de una peculiar forma de capitalismo arcáico. La estructura de la propiedad cambió radicalmente, pero no para crear como habían anunciado los reformistas del siglo XVIII una "clase de pequeños propietarios prósperos y laboriosos" (TUÑON DE LARA, M., 1974). La burguesía comercial y, sobre todo, especuladora, sustituyó a la iglesia y a la nobleza en la propiedad de la tierra. Para ello contó con la

* Nos estamos refíriendo, por ejemplo, al proceso de conversión de tierras eclesiásticas beneficiales - vinculadas por tanto- en tierras patrimoniales, efectuado en fechas anteriores a los decretos desamortizadores de tales bienes. Como también a la conversión, por el mecamismo de la arbitración, de muchas tierras comunales en tierras de propios y por tanto desamortizables (OJEDA RIVERA, J.F., 1984). 
colaboración de muchos antiguos señores laicos y eclesiásticos que por su mentalidad y forma de proceder se habían convertido de hecho en verdaderos burgueses. En definitiva los grandes propietarios dejaron de ser señores feudales para convertirse en "señoritos" capitalistas.

Los reformistas burgueses habían partido de una necesidad: la alimentación de la creciente población que no era solventada ya por la agricultura feudal. Dos son los instrumentos con los que cuentan para cubrir el objetivo propuesto: la apropiación privada de las tierras y la extensión de las áreas cultivadas a costa del resto de usos agrarios. Esto da lugar a unos planteamientos excesivamente mecanicistas sobre los distintos espacios, que son valorados por su calidad para la producción agrícola; haciendo primar el cultivo sobre los restantes aprovechamientos agrarios: ganadería, caza, carboneo, predación en general. Las dehesas, los cotos, las áreas pastoriles del Antiguo Régimen van desapareciendo ante la presión del arado y el laboreo sistemático. A la equilibrada hetereogenidad de los paisajes municipales de la vieja tradición suceden ahora la homogenización y el productivismo agrícola, los cerramientos, las prohibiciones de aprovechamientos "secundarios"...

$\mathrm{El}$ aumento del volumen total de las producciones no significó, sin embargo, que la productividad fuese mayor que en la etapa anterior. En términos generales se mantuvo el mismo nivel de rendimiento pues no se introdujeron grandes mejoras técnicas. La propiedad latifundista obtenía unos altos beneficios de la utilización masiva de una mano de obra abundante y barata, tanto por el constante crecimiento demográfico (BERNAL, A. M., 1984) como por la existencia de unas pequeñas explotaciones que no aseguraban, por sí solas, la subsistencia a sus propietarios. Además, el ferrocarril, que permitía el traslado de los jornaleros necesarios desde otras comarcas, garantizaba en toda época del año un excedente de fuerza de trabajo. Y si a esto se añaden las ventajas conseguidas de la política proteccionista estatal y de las rentas diferenciales obtenidas por los latifundios andaluces con respecto a las tierras castellanas, se comprende por qué la inversión de capitales en la agricultura andaluza no creció, de forma significativa, con el triunfo de la revolución burguesa y por qué la "cuestión agraria", a partir de estos momentos, se relaciona exclusivamente con la problemática del Mediodía español.

Socialmente las nuevas formas de explotación, destinadas a obtener el máximo beneficio con el menor coste posible, lejos de atenuar la bipolaridad del Antiguo Régimen, la habían agudizado. Los pequeños propietarios no podían prosperar dentro de la organización capitalista de la producción y se encontraban en franco proceso de empobrecimiento. La masa de asalariado que había crecido en números absolutos, atravesaba momentos críticos, a causa de los bajos salarios y de la desaparición de los mecanismos de compensación sabiamente creados por el Antiguo Régimen. Era lógico, pués, que los últimos años del siglo XIX y las primeras décadas del XX estuviesen marcadas por las agitaciones canipesinas y la aparición del movimiento jornalero. Las 
luchas de estos jornaleros que reclaman una tierra de la que se consideran injustamente desposeídos carecieron, por lo general, de continuidad y hubo largos períodos de pasividad en ellas. Pero no por eso dejaron de conmocionar a la sociedad los "estallidos de cólera campesina" (VILAR, P., 1979).

\section{CRISIS DE LA AGRICULTURA BURGUESA Y NUEVAS REFORMAS AGRARIAS}

Pronto se volverá a hablar del problema agrario cuando apenas habian pasado unas décadas del triunfo de la revolución burguesa y de la reforma agraria que en ella había implícita. Desde fines del s. XIX se multiplicaron los proyectos reformistas en busca de mecanismos capaces de corregir las tensiones sociales. Tales proyectos nunca se aplicaron, y quizás fuese esa la intención de sus promotores, pero el análisis de sus contenidos puede ser importante para conocer los planteamientos de la burguesía ante la cuestión agraria.

Las instituciones políticas desde 1883 (creación de la Comisión de Reformas Sociales) se habían visto forzadas a intervenir aunque sólo fuese a nivel de recogida de datos y redacción de informes. En 1902, siguiendo la misma línea, dicha Comisión, convocó un concurso sobre el tema: "El problema agrario en el Mediodía de España. Conclusiones para armonizar los intereses de propietarios y obreros. Medios de aumentar la producción del suelo".

La filosofía que animó a la convocatoria del concurso refleja la posición que durante gran parte del siglo XX han mantenido las autoridades españolas ante el problema agrario y social de Andalucía. "El mismo enunciado del tema de la memoria muestra con claridad el planteamiento ideológico subyacente al citado concurso. No se trataba de buscar transformaciones radicales de las formas de la propiedad, ni de proponer fórmulas que alteraran la precaria estabilidad de la estructura social del Mediodía, sino de buscar un sistema que pernitiera evitar los conflictos campesinos a través de las mejoras técnicas capaces de elevar la productividad y "armonizar" los intereses contrapuestos de propietarios y asalariados del campo" (PEREZ LEDESMA, M., 1977).

La burguesía aceptará cualquier tipo de "reforma agraria", siempre que no afecte a la cuestión principal: el derecho a la propiedad privada, al que debe subordinarse, tanto ayer como hoy, cualquier intento de transformación. El concurso de 1902 puede ser considerado, pués, como un compéndio de las líneas maestras de la réplica burguesa a las demandas revolucionarias del jornalerismo andaluz. A la transformación radical de la estructura de la propiedad, la burguesía opuso la labor pacificadora de la religión, la revolución tecnológica - concretizada a lo largo del presente siglo en la política hidráulica-- y la formación de un tipo de pequeño propietario que actuase como 
amortiguador en la lucha de clases. Todo ello bajo la apariencia de ecuanimidad y neutralidad. La "reforma agraria burguesa" ha querido aparecer como una tercera vía conciliadora entre los intereses de patrones y obreros; sin embargo el lema que mejor le cuadra no es precisamente el de "tercera vía", sino el que Pérez Ledesma adjudica en su citado artículo a la memoria de Rodrigañez ganadora del concurso de 1902: "Reformar algo para conservarlo todo".

El sindicalismo católico ha sido otro de los instrumentos predilectos de la política agraria burguesa y, posiblemente, al desarrollar algunas de las líneas de actuación esbozadas ya en 1902, el que mejor refleja los componentes paternalistas y demagógicos que siempre han estado presentes en los intentos de reformar las estructuras agrarias desde y en favor de las clases privilegiadas.

Aunque sus orígenes haya que buscarlos en la encíclica Rerum Novarum, la consolidación de las organizaciones católicas (C.N.C.A.) en el campo español no tuvo lugar hasta el período que va desde 1917 a 1923. En esos años, que incluyen el llanado "trienio bolchevique", la conflictividad social volvió a ser especialmente grave. La aceleración de la acumulación capitalista, a raiz de la I Guerra Mundial, había agudizado las contradicciones del sistema (inflación, carestia de la vida, empobrecimiento de pequeños propietarios, arrendatarios, aparceros, etc.) y provocado así el resurgimiento del movimiento jornalero, aletargado desde 1905.

La burguesía agraria percibió pronto el peligro que para ella representaba la situación prerrevolucionaria que se vivía y la posibilidad real de una alianza entre los obreros agrícolas de una parte, y los pequeños propietarios, aparceros y arrendatarios, de otra. La salida ya no podía ser exclusivamente la represión. Era necesario intervenir en el tejido social para frenar el avance anarquista y socialista, creando él verdaderos antídotos antirrevolucionarios. Y como tales fueron concebidos los Sindicatos Agrarios Católicos que, además contaban para ello con la labor que desde hacía siglos venía realizando la Iglesia entre los campesinos (CASTILLO, J.J., 1979).

El objetivo de esta peculiar forma de "reforma agraria" fué el de ampliar y fortalecer la masa social conservadora en el campo y, por lo tanto, reforzar la posición de la gran propiedad. El camino escogido fue el de proteger a la clase de los propietarios pobres para evitar, de esa manera, su proletarización -créditos de las Cajas Rurales, defensa de los precios agrícolas...- y el de permitir el acceso a la propiedad de los aparceros, arrendatarios y jornaleros, conscientes de que "la línea de separación entre los campesinos revolucionarios y los conservadores no hay que buscarla en el nivel de vida de unos y otros, sino en la ilusión de independencia que proporciona la propiedad de la tierra" (MALEFAKIS, E., 1970). 
El concepto de "reforma agraria" elaborado por esta corriente del catolicismo ha llegado a convertirse en la fórmula preferida por la gran propiedad y el Estado para abordar el problema social agrario. Con ella, por una parte, se acaba con el peligro revolucionario: los obreros agrícolas quedan aislados de los restantes grupos de explotados y pueden ser contenidos con la esperanza de recibir una tierra propia, mientras que los pequeños propietarios, protegidos por el Estado y el Sindicato, se convierten en los primeros defensores del orden establecido; y por otra, la gran propiedad se hacía de unos aliados fieles con los que formar un "sector agrario" supuestamente interclasista, pero que siempre contará con una dirección de clase, a través del cual presentar unas reivindicaciones (barreras arancelarias, precios mínimos, subvenciones, etc.) al Estado y la sociedad que por otras vías difícilmente hubiesen podido ser aceptadas.

En la práctica, como se verá más adelante, la "armoniosa solución" de convertir al jornalero en propietario no hace más que cambiar la forma de explotación de aquel, pero no acaba con ella. La independencia del propietario que cultiva directamente sus tierras es, hoy por hoy, más ficticia que real y su grado de explotación por la gran propiedad, y el capital en general, no mucho menor que el del obrero asalariado.

La filosofía del sindicalismo católico ha trascendido en importancia a las actuaciones concretas de las organizaciones a que dió lugar. Su influencia ha estado presente en la Colonización Interior de Primo de Rivera, en la Ley de Reforma Agraria de la II República, en la política colonizadora del Régimen de Franco, y, sorprendentemente, en las proclamas de la izquierda política y sindical actual (ZOIDO, F., 1983).

Hasta la II República, la preocupación por la mejora de la agricultura se canalizó, pues, en dos direcciones: Política hidráulica y Colonización y Repoblación interior. El "milagro" del agua, muy repetido en las esferas intelectuales y de poder desde J. Costa, el papel armonizador que se había asignado a la pequeña propiedad familiar y el recurso al pinar como sustitutivo de los antiguos bosques, propiciado por el Cuerpo de Ingenieros de Montes, hacían teóricamente coherente una política de actuación agraria que, en la práctica, continuaba dando lugar a la progresiva homogenezación de áreas paisajísticas desarticuladas entre sí y al despilfarro ecológico y energético.

En resumen, la actitud de los diferentes gobiernos ante la "cuestión agraria" en este período histórico se caracteriza por la primacia de lo técnico y por el paternalismo social, con lo que al no tocar las bases del sistema, la problemática de fondo seguía sin resolverse, lo que explica que con la proclamación de la II República se vuelva a plantear abiertamente.

Enlazando con las preocupaciones de igualitarismo social, confinadas hasta este momento en las mentes de intelectuales y políticos avanzados, los agraristas de la II República consideran como objetivo primordial de la Ley de Reforma Agraria la redistribución de tierras y el asentamiento en ellas de 
campesinos. Las tierras de la nobleza, que todavía prevalecían como reliquias de un pasado ya remoto, ofrecían a los republicanos una oportunidad de iniciar tal reforma sin enfrentarse directamente a los intereses de las clases burguesas. El antimonarquismo y el odio a la aristocracia, reinantes en las clases populares, daban a su vez un matiz populista a la medida de expropiar sin indemnización las fincas de los nobles.

Pero en realidad, la Ley de 1932, en lo que se refiere a sistemas de expropiación e indemnización, no resulta muy avanzada para su tiempo si se compara con otras leyes agrarias de la Europa de los años 20, preparadas casi todas ellas por gobiernos conservadores (TAMAMES, R , 1980).

La separación entre gobernantes reformistas y campesinos fue ahondándose de forma progresiva. La lentitud de la realización y sus resultados no correspondían ni con mucho a las esperanzas puestas en la Ley por aquellos últimos. A la burguesía, como se pretende demostrar en este artículo, le interesa revisar de vez en cuando la cuestión agraria, sacándola a la luz, pues tiene necesidad de "reformar para que nada cambie", pero ello no supone en ningún caso una concesión para cambiar en profundidad el sistema ni la estructura que lo sostiene.

Fue necesaria la ocurrencia de una serie de hechos excepcionales que llevaron a una situación bélica, para que los campesinos tomen las riendas de la reforma y, superando a los mismos "reformistas", lleven a cabo una serie de experiencias muy coyunturales, pero que quedarán como verdaderos hitos de lo que puede denominarse con toda propiedad Reforma Agraria en la historia de España.

La política del gobierno triunfante en la guerra significa un nuevo paso de la reforma jurídico-social a la reforma técnica. Los objetivos ya apuntados en la Restauración y los albores de la centuria actual son de nuevo retomados. Las siglas del organismo encargado de la cuestión agraria - - I.N.C./I.R.Y.D.A.-son la expresión más inmediata de la asimilación del concepto de reforma al de desarrollo. Tras las veleidades del período bélico se vuelve a la idea primigenia del sistema burgués: Reformar no es más que desarrollar y desarrollar es producir.

La permanencia de latifundios en el sentido más peyorativo de la palabra, o sea de explotaciones retardadoras de dicho desarrollo, dió lugar a la Ley de 1953 -Fincas Manifiestamente Mejorables- que cumple además una función de imagen del nuevo régimen de cara al exterior.

Serán los años 60 y principios de los 70 los que marquen un panorama apareńtemente esperanzador en la solución de los problemas seculares de nuestra agricultura, aunque de forma paradógica, se le está condenando a una definitiva dependencia del exterior. 
Apoyando la idea de la formación de "grandes empresas agrícolas" se pretende insertar la agricultura plenamente dentro de la estructura económica global del país, aunque ello suponga un desprecio absoluto por la protección de los ecosistemas y un elevado derroche energético. No se duda en fomentar el éxodo de pequeños y medianos campesinos que, al vender sus propiedades y abandonar el campo, posibilitan el desarrollo de una política de concentración parcelaria. Esto no es óbice para promocionar al mismo tiempo un minifundismo localizado en determinadas zonas regables, allí donde las grandes explotaciones requieren abundante mano de obra agrícola y ocasional. En definitiva, la emigración de una gran masa de jornaleros y campesinos y el surgimiento de nuevas actividades alternativas a las del campo - turismo, construcción, industrias- dan lugar a una mitigación del problema del paro y a un cierto aumento de los salarios reales de los campesinos (BERNAL, A.M., 1984. 2).

Este panorama de "desarrollo económico general" hace olvidar por algún tiempo la cuestión agraria. Parece como si el problema de la reforma agraria hubiese sido superado, quedando relegado a la memoria de un pueblo, no a la realidad.

La crisis de los 70 pone en evidencia el espejismo del panorama anterior. Los mecanismos de drenaje poblacional quedan paralizados, produciéndose con la vuelta de los emigrados un efecto contrario. El aumento del paro y la conflictividad laboral vuelven a convertirse en los grandes protagonistas de la situación y, una vez más, aparecen la "reforma agraria" y el "reparto" como las esperadas soluciones a la crisis.

Las diversas opciones políticas andaluzas captan el carácter carismático del término "reforma agraria" asumiéndolo dentro de sus programas regionales. Precisamente el uso indiscriminado de este símbolo hará confusa e imprecisa su conceptuación, pués en él se mezclan elementos de las tradicionales y repetidas "reformas agrarias burguesas" - aumento de la productividad, modernización, integración en la C.E.E...- con elementos aparentemente revolucionarios y socializantes -función social de la tierra, impuestos sobre tierras infrautilizadas, expropiaciones...--

Las posibilidades reales de una reforma agraria quedan reflejadas en el Estatuto de Autonomía Andaluz que - en su art. 12, apartado 3.0, n. ${ }^{\circ} 11-$ la consagra como objetivo básico de la Comunidad Autónoma entendiéndola "como la transformación, modernización y desarrollo de las estructuras agrarias y como instrumento de una política de crecimiento, pleno empleo y corrección de los desequilibrios territoriales".

Este marco institucional solo parece pretender la inserción plena de la agricultura en el modo de producción imperante, adecuándola a las contínuas espectativas de entrada en la C.E.E., pero no ofrece posibilidades para 
una alteración sustancial de la estructura de propiedad vigente. Sin embargo, las diferentes lecturas de dicho marco admite como "legales" a dos grupos de programas de reforma:

- Uno, el triunfante, representado por un amplio espectro que va desde A.P. a P.S.O.E., que considera "...que la agricultura andaluza contiene potencialidades capaces de hacerla asumir un papel protagonista mayor en el desarrollo económico propiciando un reordenamiento general de la economía y sociedad en base a las especificaciones y posibilidades agroindustriales, siendo necesario para ello proceder a una transformación profunda de la llamada estructura agraria, sobre todo en lo que a explotación, cultivo y fiscalidad se refiere..." (BERNAL, A.M., 1984.2).

- Otro, el alternativo, que "valorando más la influencia social que el factor tierra-agricultura tiene todavía en Andalucía y asumiendo la línea argumental reformista de formaciones políticas de izquierda y de sindicatos de clase, propugna que la tierra no cumplirá la 'adecuada función social' si previamente no cambia y transforma su régimen de propiedad" (BERNAL, A.M., 1984.2).

\section{EPILOGO DE UNA LARGA TRAYECTORIA}

La historia de la agricultura en el sistema capitalista vuelve, pues, a presentar unos componentes similares a los de siempre: proyecto burgués frente a proyecto alternativo de reforma agraria.

En la actualidad, parece ser la entrada en la C.E.E,, el objetivo inmediato de la burguesía dominante y para conseguirlo no duda en reconvertir y organizar, planificar y modernizar todos los sectores económicos. La hora de una "nueva reconversión-reforma" - una más de la serie secular - ha llegado a la agricultura y especialmente a la andaluza que debe adaptarse a los cánones de dependencia exterior que exige el "alto nivel de desarrollo" requerido por la C.E.E.: hay que modernizarse, hay que producir, hay que exportar compitiendo.

Pero al proyectar esta reconversión no se emplea por ninguna de las partes implicadas, la lógica de los sistemas económicos que cada opción política considera como ideal. Así puede observarse cómo, desde posiciones conservadoras, no se olvida el paternalismo heredado ni las necesidades de voto y se apoyan a las pequeñas y medianas explotaciones agrarias que, según cualquier sencillo análisis, representan el gran impedimento para los avances capitalistas en el sector. Dichos apoyos resultan, pues, claramente contradictorios con la lógica capitalista de promocionar monopolios, hacer crecer propiedade y explotaciones e introducir, en definitiva, las leyes de competitividad y 
reproducción ampliada en este sector productivo como lo ha hecho en el resto de los sectores. A su vez, las opciones de izquierda - empujadas también por el electoralismo- defienden la apropiación privada de la tierra por pequeños y medianos campesinos y olvidan - tal vez constreñidas por el hecho constitucional de defensa de la propiedad privada- su genuina reivindicación nacionalizadora y contraria a dicha apropiación privada. Ahora bien, de cara a la galeria y para salvar sus conciencias --pues ni los mismos gestores de sus programas pensarán que por este camino puedan darse muchos pasos sin chocar con la actual Constitución española- usan o abusan de una norma excepcional de dicha carta constitucionaì (la "función social" del artículo 33) para mantener en pie su clásica bandera.

Todos, en fin, como buenos burgueses coinciden en la necesidad de cubrir unos imperativos básicos: la modernización y el desarrollo. Pero ninguno explica lo que significa estas palabras casi mágicas. Se utilizan como frases retóricas cuyos significados fuesen obvios. Sin embargo, después de la crisis de 1973 , ese planteamiento no concuerda ya con la realidad pues hoy no existe un "patrón claro e inapelable de modernidad". Por lo tanto no se puede seguir elaborando leyes sobre principios que cuando menos requieren una profunda revisión crítica. Algunos, quizás con razón, descalifican el lema jornalero de "la tierra para quien la trabaja" como consigna superada por el propio peso de la historia, sin darse cuenta de que sus propuestas de "modernización" deben sufrir el mismo proceso de reciclaje.

Estamos de acuerdo por el momento con aquellos que afirman que "a raíz de la crisis energética, ecológica y de recursos se desarrolló un conjunto de trabajos que evidenciaron la imposibilidad de generalizar a escala planetaria actitudes, tecnologías y patrones de consumo que hasta hace poco se tomaban como paradigma de modernidad y que ahora aparecían presumiblemente obsoletos, al ser incapaces de asegurar a largo plazo y para el conjunto de la especie humana, una alimentación sana y abundante... constituye un flaco servicio a la causa de la modernidad ignorar la crisis que está atravesando lo que se venía considerando como moderno" (NAREDO, J.M., 1983). Pues bien, esto último precisamente es lo que han hecho la inmensa mayoría de las fuerzas políticas y sindicales andaluzas, incluídas las de izquierda, aquellas a las que cabría suponer una mayor capacidad de crítica ante el desarrollo capitalista.

De esta forma se ha escamoteado una cuestión que debería ser básica en un debate sobre la reforma agraria en el último cuarto del siglo XX, es decir, el modelo de desarrollo a seguir (ALBURQUERQUE, F., 1984). En dicho debate cabrían al menos dos grandes opciones: Una es la representada por la "revolución verde" que llevaría a una agricultura industrializada. La segunda sería la conocida con el nombre de "agricultura biológica". 
Las diferencias entre ambas no son puramente tecnológicas - uso intensivo de medios químicos frente a métodos naturales- sino también y esencialmente filosóficas:

- En el caso de la agricultura industrializada se persigue un beneficio parcial (de los propietarios de las explotaciones, de las empresas químicas y mecánicas, de las grandes agroindustrias, de las clases y regiones más favorecidas, etc...) y a corto plazo (se desprecia el efecto de unas prácticas agrícolas depredadoras del medio natural: erosión, contaminación, pérdida de la fertilidad, etc...) que difícilmente puede ser duradero a causa del despilfarro energético que representa.

- La agricultura biológica intenta, por el contrario, conseguir un equilibrio entre la acción humana y el medio. Para ello tiene que, forzosamente, romper con el modelo de desarrollo seguido hasta la fecha: consumo desenfrenado, olvido de los ciclos biológicos de la naturaleza, etc... A cambio se debe de conseguir un desarrollo más armónico del que se beneficie la totalidad de la sociedad y que, a largo plazo, es mucho inás estable.

En definitiva, el recurso a la historia nos ha llevado en este seminario a comprender que quizás no sea retrógrado mirar atrás y descubrir los principios armonizadores que iluminaban la agricultura tradicional. El valor ecológico y profundamente articulador de terruños y economías distintas que poseen una dehesa, un ruedo, o un sistema de cultivo al tercio típico de los cortijos andaluces, puede resultar un buen modelo a seguir en su concepción de respeto al ciclo biológico como carácter distintivo de la actividad agropecuaria. Vuelta atrás y desarrollo no tienen porque ser conceptos enfrentados sino -como ejemplos de la dialéctica de lo real- perfectamente paralelos, si - tras una profunda reflexión imaginativa- se consiguen tomar como camino de futuro los principios de actuación tradicionales y la tecnología proporcionada por el desarrollo científico. 


\section{BIBLIOGRAFIA CITADA}

ALbURquerquE, F.: "Andalucía, un desarrollo dificil" en Revista de Estudios Andaluces. Sevilla, 2, 1984, pp. 59-72.

BER NAL, A.M.: "De nuevo la Reforma Agraria" Nación Andaluza 2-3. Granada, 1984. págs. 9-13.

"Desarrollo económico y desequilibrio regional en Andalucía: la incidencia del sector agricola" Rcvista de Estudios andaluces 2, Sevilla, 1984, págs. 15-30.

CASTILLO, J.J.: "Propictarios muy pobres" Ministerio de Agricultura, Madrid, 1979, 572 págs.

CLAVERO, B.: "Política de un problema: la revolución burguesa" en Clavero, B. y otros. Estudios sobre la revolución burguesa en España. Madrid, s. XXI, 1979, págs. 3-48.

FONTANA, J.: "La crisis agraria de comienzos del s. XIX y sus repercusiones en España" en Revista de Hacienda pública española. Madrid, Ministerio de Hacienda, 1978, 55, págs. 177-190.

LOPEZ ONTIVEROS, A.: "Actividad agraria y medio ambiente" en Geografía y Medio Ambiente. Madrid, MOPU, 1984, págs. 213-253.

MALEFAKIS, E.: "Reforma agraria y revolución campesina" en La España del $S$. $X X$, Barcelona, Ariel, 1970, págs. 523.

NAREDO, J.M.: "La crisis del olivar como cultivo "biológico" tradicional" en Agricultura y sociedad. Madrid, Ministerio de Agricultura, 1983, 26, págs. 168-288.

OJEDA RIVERA, J.F.: "Organización del espacio en el litoral suronubense. Almonte (Huelva) ss. $X V I I I-X X "$ ". Sevilla, Departamento de Geografía, Tesis de doctorado en elaboración.

OLAVIDE, Pablo de: "Informe de Olavide sobre la ley agraria" (Expediente o memorial 1768-77). Ed. Carande, R. Boletín de R.A.H. Madrid, 1956, págs. 357-462. (CXXXIX).

PEREZ LEDESMA, M.: "El problema agrario en Andalucía a comienzos de siglo" en Agricultura $y$ socicdad. Madrid, Ministerio de Agricultura, Abril-Junio 1977, págs. 245-351.

SIMON SEGURA, F.: "La desamortización española del siglo XIX". Madrid, Ministerio de Hacienda, 1973, págs. 523.

TAMAMES, R.: "Estructura económica de España". Madrid, Alianza Ed., 1980, Tomo I, págs. 1.249.

TARRAFETA PUYAL, L.: "La capitalización de la agricultura española, 1962-1975". Madrid, Publicaciones del Banco de Crédito Agrícola, 1979, págs. 418.

TOMAS Y VALIENTE, F.: "El marco politico de la desamortización en Esparia". Barcelona, Ariel, 1977 , págs. 172.

TUÑ ON DE LARA, M.: "La España del siglo XIX". Barcelona, Laia, 1974, págs. 300.

VILAR, P.: "Historia de España". Barcelona, Grijalbo, 1979. Págs. 173.

ZOIDO, F.: "Explotación familiar e intervención del Estado, ejemplos de los nuevos regadíos béticos" en Formación y utilización de recursos humanos en Andalucia. Sevilla, Instituto de Desarrollo Regional. Universidad de Sevilla, 1983, 25, págs. 419-435. 